\title{
Cochlodinium Polykrikoides 최적 성장모형 Optimal Growth Model of the Cochlodinium Polykrikoides
}

\author{
조홍연*·조범준** \\ Hong-Yeon Cho* and Beom Jun Cho**
}

\begin{abstract}
요 지: Cochlodinium polykrikoides 적조생물은 우리나라 연안에서 가장 빈번하게 적조를 유발하는 생물이다. 적 조는 식물플랑크톤의 급격한 번식(algal bloom)으로 발생하기 때문에 적조를 유발하는 적조생물에 대한 최적의 성 장조건 정보가 가용하다면 정확한 적조성장 모형 구성이 가능하며, 적조 발생예측에도 활용할 수 있다. 그러나 적 조 성장에 영향을 미치는 인자가 빛, 수온, 염분, 영양염류 농도 등으로 다양하고, 적조성장을 제어하는 함수형태가 다양하기 때문에 실험조건의 최적 성장조건에 대한 연구 성과를 활용하여 적조 수치모형에서 활용할 수 있는 최적 성장모형을 구성한 연구는 매우 미흡한 수준이다. 본 연구에서는 우리나라의 대표적인 적조생물에 해당하는 Cochlodinium polykrikoides 적조생물의 최적 성장조건에 관한 연구 자료를 이용하여 다양한 함수형태에 따른 최적 매개변수 추정 및 오차비교·분석과정을 거쳐 적조 모형에서 바로 활용할 수 있는 최적 성장모형을 개발·제시하였다. 개발된 성 장모형은 실험조건에서 추정된 최적 성장모형이기 때문에 현장자료를 이용한 모형의 보정 및 검정과정에서 본 연 구결과로 제시된 최적 함수형태, 최적 매개변수 및 보정 매개변수의 범위 등을 기본 정보로 활용할 수 있으며, 실 험조건과 현장조건의 차이 평가에도 활용할 수 있다.
\end{abstract}

핵심용어: Cochlodinium polykrikoides, 최적 성장조건, 영향인자, 매개변수 추정, 적조모형

\begin{abstract}
Cochlodinium polykrikoides is a typical harmful algal species which generates the red-tide in the coastal zone, southern Korea. Accurate algal growth model can be established and then the prediction of the red-tide occurrence using this model is possible if the information on the optimal growth model parameters are available because it is directly related between the red-tide occurrence and the rapid algal bloom. However, the limitation factors on the algal growth, such as light intensity, water temperature, salinity, and nutrient concentrations, are so diverse and also the limitation function types are diverse. Thus, the study on the algal growth model development using the available laboratory data set on the growth rate change due to the limitation factors are relatively very poor in the perspective of the model. In this study, the growth model on the C. polykrikoides are developed and suggested as the optimal model which can be used as the element model in the red-tide or ecological models. The optimal parameter estimation and an error analysis are carried out using the available previous research results and data sets. This model can be used for the difference analysis between the lab. condition and in-situ state because it is an optimal model for the lab. condition. The parameter values and ranges also can be used for the model calibration and validation using the in-situ monitoring environmental and algal bloom data sets.
\end{abstract}

Keywords: Cochlodinium polykrikoides, optimal growth condition, limitation factor, parameter estimation, algal bloom (red-tide) model

\section{1. 서 론}

해양수산부에서는 적조에 의한 수산피해방지를 위한 대책 수립에 필요한 사항을 결정하고, 효과적으로 대책업무의 효 과적인 추진을 위한 훈령을 제시하고 있다(Ministry of Oceans and Fisheries, 2014). 이 훈령은 적조 예찰 · 예보 및 피해방지에 대한 요령을 제시하고 있으며, 신속한 적조예찰,
적조특보 발령 및 적조대책본부를 구성하여 운영하는 내용을 포함하고 있다. 적조는 연안의 어떤 특정 지점에서 발생한다 할지라도 흐름을 따라 이동하거나 환경조건에 따라 증식 또 는 소멸되는 양상을 보이기 때문에 현장 관측 자료를 이용하 거나 모형을 이용하여 적조의 이동경로 및 적조의 성장.소 멸에 의한 규모변화 또는 영향범위를 예상하여 대책을 수립 하는 것이 바람직하다. 일반적으로 적조생물은 유영능력이 없

* 한국해양과학기술원 해양환경보전연구부 (Marine Environment and Conservation Research Division, Korea Institute of Ocean Science and Technology)

** 한국해양과학기술원 해양환경보전연구부 (Corresponding author : Beom Jun Cho, Marine Environment and Conservation Research Division, Korea Institute of Ocean Science and Technology, 787 Haeanro, Ansan, Gyeonggi, 426-744, Korea. Tel:+82-31-400-7807, Fax.:+82-31-400-7868, bjcho@kiost.ac) 
는 생물로 간주되기 때문에 이동양상은 정확한 흐름모의를 통 하여 예측이 가능하다. 그러나 적조생물의 시간에 따른 번식. 소멸은 흐름과 더불어 광도(light intensity), 수온, 염분, 영양 염류 농도와 같은 환경조건과 적조의 생리적인 특성 등이 지 배하기 때문에 환경조건 및 생태학적인 특성 등을 반영하여 적조의 규모변화를 예측하여 영향범위를 제시하여야 한다 (Seoul National University, 2014). 그러나 적조의 성장조건 은 적조생물에 따라 서로 다르기 때문에 하나의 성장모형을 이용하여 적조의 규모를 예측하는 경우 상당한 오차가 발생 하게 된다. 따라서 모든 적조생물에 대하여 환경조건이 성장 에 미치는 영향을 분석하여 추정된 정보를 이용하는 것이 바 람직하나 가용한 정보가 제한되어 있다. 한편, 어떤 특정한 적 조생물의 경우에도 단편적인 환경조건에 대한 정보나 자료가 제시되어 있으나 주어진 자료를 이용하여 적조의 규모변화 예 측에 적합한 요소 모형(element model)으로 제시되는 경우는 매우 미흡한 수준이다. 또한 적조생물의 성장-소멸에 관한 수 학적인 표현은 다양하게 제시되고 있으나, 정량적인 변화양 상을 표현하는 매개변수 정보는 상대적으로 미흡하기 때문에 실용적인 모형 개발 측면에서 정량적인 매개변수 추정이 요 구된다(Jorgensen and Bendoricchio, 2001). 그러나 적절한 성장모형만 구성되고 환경조건 정보가 지원되는 경우 적조의 이동경로와 더불어 규모변화도 예측이 가능하여 효과적인 적 조피해 방지대책 추진이 가능하다.

본 연구에서는 우리나라에서 최근 가장 빈번하게 적조를 유 발하는 생물로 지목되는 Cochlodinium polykrikoides (이하 $C$. polykrikoides) 적조생물(Lee et al., 2013)에 대한 성장모형을 개발하는 것을 목적으로 한다. C. polykrikoides 성장 모형개 발에 사용한 자료는 다양한 환경조건에서의 C. polykrikoides 적조생물의 성장변화 연구 성과이다. 다양한 환경조건에 따 른 적조생물의 성장변화 연구는 실험실에서 환경조건을 변화 시켜가며 적조생물을 배양하는 방법으로 수행되었으며, 성장 모형의 관점에서는 부품 또는 자료수준의 성과이기 때문에 가 용한 자료를 조합하여 현장에서 사용할 수 있는 성장 모형을 제시하는 연구는 매우 미흡한 수준이다.

\section{2. 자료 및 방법}

\section{1 환경조건에 따른 C. polykrikoides 성장률 자료}

일반적으로 조류 또는 식물플랑크톤의 성장을 제한하는 인 자는 광도, 수온, 영양염류의 농도 및 염분이다. 특히 수온 및 광도는 최적조건이 존재하는 경우가 있어 현실적인 변화범위 에서 최적조건을 찾아내는 연구가 활발한 실정이다. 본 연구 에서는 C. polykrikoides 적조생물에 대한 환경조건과 성장률 관련 문헌(Table 1 참조)을 모두 수집하여 성장모형 구성을 위한 자료를 그림에서 독취하거나 제시된 수치자료를 추출하 였다. 수집된 연구 자료는 환경인자도 다양하고, 변화범위도 다양하기 때문에 자료에 따라 성장모형을 구성하는 매개변수
의 추정 결과에도 차이가 발생할 수 있다. C. polykrikoides 표본 채취 해역에 대한 정보는 Table 2에 제시하였다. 현장 환경인자 관측 자료와 적조생물의 농도변화를 분석하여 성장 변화를 파악하는 연구도 활발하게 수행되고 있으며(Lim, 2004), 매우 실질적인 방법으로 판단된다. 그러나 정성적인 성 장양상 분석 및 모형의 현장적용에 따른 보정 및 검정 측면 에서는 적합하나 정량적인 성장 모형의 구성 및 계수 추정에 는 부적합하여 본 연구에서 구성하는 성장 모형 구성을 위한 활용자료세트에서는 제외하였다.

\section{2 성장모형의 함수형태 및 매개변수 추정}

일반적으로 제시되는 조류 성장모형은 다음과 같은 식 (1) 로 표현할 수 있다.

$$
G_{P}=\mu_{\max } f_{1}(I) \cdot f_{2}(T) \cdot f_{3}(S) \cdot f_{4}(N)
$$

여기서 $G_{P}$ 는 주어진 환경조건에서의 적조생물 성장률(growth rate, $1 /$ day)이며, $\mu_{\max }$ 는 최적 환경조건에서의 가능한 조류성장 률(1/day)로 최대 조류 성장률이라고 한다. $f_{i}(i=1,2,3,4)$ 함수는

Table 1. References on the Cochlodinium polykrikoides growth rate

\begin{tabular}{|c|c|c|c|c|c|c|}
\hline \multirow{3}{*}{$\begin{array}{l}\text { Reference } \\
\text { Codes }\end{array}$} & \multicolumn{6}{|c|}{ Environmental factors } \\
\hline & \multirow{2}{*}{$\begin{array}{l}\text { Light } \\
\text { intensity }\end{array}$} & \multirow{2}{*}{$\begin{array}{l}\text { Water } \\
\text { tempera- } \\
\text { ture }\end{array}$} & \multirow[b]{2}{*}{ Salinity } & \multicolumn{3}{|c|}{ Nutrients } \\
\hline & & & & $\mathrm{NO}_{3}$ & $\mathrm{NH}_{4}$ & $\mathrm{PO}_{4}$ \\
\hline O2010 & $\bigcirc$ & $\triangle$ & $\triangle$ & $x$ & $x$ & $x$ \\
\hline $\mathrm{O} 2006$ & $\bigcirc$ & $\times$ & $\times$ & $\times$ & $\times$ & $\times$ \\
\hline K2001 & $\bigcirc$ & $\bigcirc$ & $\bigcirc$ & $\bigcirc$ & $\bigcirc$ & $\bigcirc$ \\
\hline L2001 & $\bigcirc$ & $\bigcirc$ & $\bigcirc$ & $\bigcirc$ & $\bigcirc$ & $\bigcirc$ \\
\hline Y2005 & $\bigcirc$ & $\bigcirc$ & $\triangle$ & $\times$ & $\times$ & $\times$ \\
\hline K2004 & $\bigcirc$ & $\triangle$ & $\triangle$ & $\times$ & $\times$ & $\times$ \\
\hline G2012 & $\times$ & $\times$ & $\times$ & $\bigcirc$ & $\bigcirc$ & $\bigcirc$ \\
\hline
\end{tabular}

Ref.: Reference Code, O2010 $=$ Oh et al. (2010); O2006 $=$ Oh et al. (2006); K2001=Kim et al. (2001); L2001=Lee et a1. (2001); Y2005=Yamatogi et al. (2005); K2004=Kim et al. (2004); G2012=Gobler et al. (2012); Graphic symbol: $\bigcirc=$ Contour data, $\triangle=$ Graph data, and $\times=$ No data

Table 2. Coastal seas of the $C$. polykrikoides sampling stations

\begin{tabular}{cc}
\hline $\begin{array}{c}\text { Reference } \\
\text { Codes }\end{array}$ & Sampling coastal seas \\
\hline O2010 & Yokjido coastal seas, Korea (2008. 8) \\
O2006 & Inokushi Bay entrance, Kyushu, Japan (2005. 3.) \\
K2001 & Southern coastal seas in Korea (1996) \\
L2001 & Southern coastal seas from Wando to Busan, \\
& Korea (1999) \\
Y2005 & Western Kyushu coastal seas, Japan \\
K2004 & Furue Bay, Nagasaki, Japan (2001. 1) \\
G2012 & Flanders Bay, New York, USA (2006) \\
\hline
\end{tabular}


Table 3. Limitation function types on the algal growth model

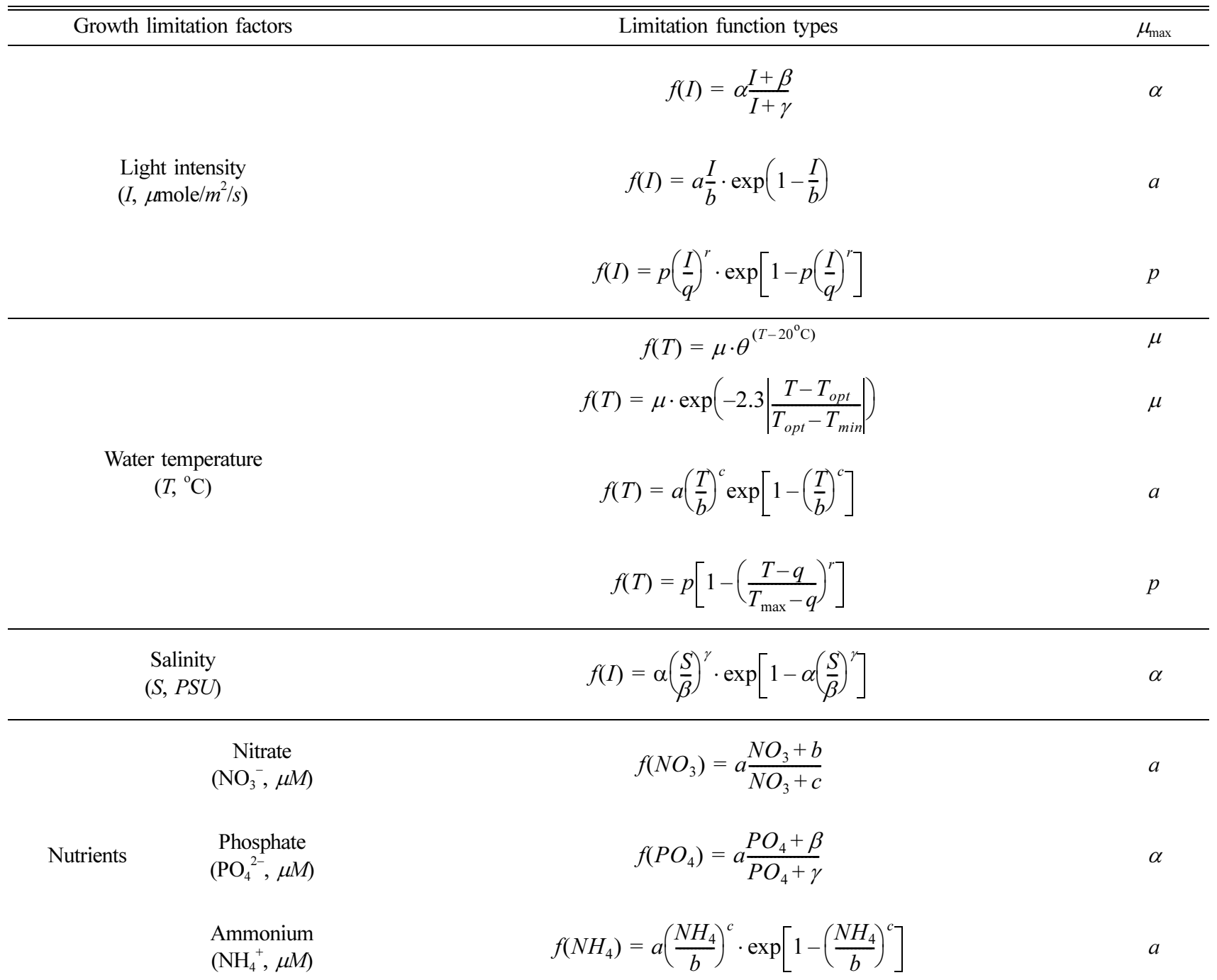

Ref. $T_{\min }$ and $T_{\max }$ can be estimated optimally as the model parameters, though these values also can be estimated with ease using each data set

각각 $i$ 환경조건 $(I=$ 광도, $T=$ 수온, $S=$ 염분, $N=$ 영양염류 농도)에서의 성장 양상을 표현하는 함수이며, 환경조건에 따 라 다양한 함수로 제시된다(Table 3 참조). 영양염류 농도는 다시 암모니아, 질산염, 인산염으로 세분할 수 있으며, 각각 유사한 형태의 성장함수로 표현할 수 있다. 본 연구에서는 다 양한 함수를 이용하여 비선형최적화 기법을 이용하여 각각의 자료와 전체 자료를 이용하여 최적 매개변수와 RMS(rootmean squared) 오차를 추정하였으며, 최적 성장모형으로는 $\mathrm{RMS}$ 오차가 가장 작은 함수모형을 선택하였다. 최적 매개변 수 추정을 위한 목적함수는 관측 자료와 모형추정 자료의 차 이의 제곱합(sum of squares)으로 결정하였으며, MATLAB 프로그램에서 제시하는 'Isqcurvefit' 함수를 이용하여 최적 매 개변수를 추정하였다.

\section{3. 결과 및 토의}

다양한 환경조건에서 수행된 각각의 자료를 이용하여 Table 2 에 제시된 함수의 최적 매개변수를 추정하였다. 추정결과 함
수의 형태가 자료의 변동양상을 크게 벗어나는 함수는 분석 에서 제외하였으며, 전체적인 변동양상이 유사한 함수를 대 상으로 최적 매개변수를 추정하였으며, 각각에 대한 매개변 수 추정결과 및 RMS 오차를 Table 4-7에 제시하였으며, 실 험 자료와 모형 자료의 비교 그림은 전체자료를 이용한 경우 와 가장 작은 RMS 오차를 제시하는 자료를 비교하여 Fig. 1 에 제시하였다. 한편 본 논문에서 제시한 최적 매개변수 추 정결과는 각각의 문헌 자료를 이용한 경우는 동일한 형태의 함수를 이용하는 경우와 당연히 일치하지만, 대부분의 문헌 에서 자료만을 제시한 경우가 많고, 본 연구에서는 전체자료 를 이용한 검토도 수행하였기 때문에 기존 연구결과에서 제 시하는 수치와의 비교검토는 생략하였다.

광도변화에 따른 조류(algae) 성장률 변화곡선은 MichaelisMenten 형태의 함수(saturation curve)와 광저해 효과를 고려한 함수(photo-inhibition curve)의 형태가 일반적으로 사용되고 있 다(Bowie et al., 1985). 각각의 함수는 반포화광도, 최적 광도 에 해당하는 매개변수 추정이 필요하다. 본 연구에서는 광도에 따른 C. polykrikoides 성장률 변화곡선으로 약간 변형된 형태 
Table 4. Optimal parameter values and RMS errors of the $C$. polykrikoides growth rate in the light intensity conditions for each data set

\begin{tabular}{|c|c|c|c|c|c|c|c|}
\hline \multirow[t]{2}{*}{ Reference data } & \multicolumn{4}{|c|}{$f(I)=\alpha \frac{I+\beta}{I+\gamma}$} & \multicolumn{3}{|c|}{$f(I)=a \frac{I}{b} \exp \left(1-\frac{I}{b}\right)$} \\
\hline & $\alpha$ & $\beta$ & $\gamma$ & RMSE & $a$ & $b$ & RMSE \\
\hline O2010 & 0.30 & -15.33 & 27.07 & 0.012 & 0.27 & 244.59 & 0.028 \\
\hline $\mathrm{O} 2006$ & 0.34 & -14.05 & 8.64 & 0.017 & 0.33 & 192.77 & 0.026 \\
\hline L2001 & 0.58 & -2.01 & 16.60 & 0.033 & 0.49 & 74.99 & 0.040 \\
\hline K2001 & 0.45 & -11.54 & 6.19 & 0.005 & 0.40 & 127.59 & 0.034 \\
\hline K2004 & 0.32 & -9.49 & 9.55 & 0.021 & 0.30 & 139.06 & 0.022 \\
\hline Y2005 & 0.53 & -5.23 & 17.80 & 0.030 & 0.45 & 109.27 & 0.031 \\
\hline Total data & 0.41 & -4.70 & 15.41 & 0.091 & 0.38 & 119.86 & 0.083 \\
\hline
\end{tabular}

Ref. Unit of $\alpha, a$, and RMSE $=[1 /$ day $]$. Unit of $\beta, \gamma$, and $b=\mu \mathrm{mole} / \mathrm{m}^{2} / s$

Table 5. Optimal parameter values and RMS errors of the C. polykrikoides growth rate in the water temperature conditions for each data set

\begin{tabular}{|c|c|c|c|c|c|c|c|c|}
\hline \multirow[t]{2}{*}{ Reference data } & \multicolumn{4}{|c|}{$f(T)=a\left(\frac{T}{b}\right)^{c} \exp \left[1-\left(\frac{T}{b}\right)^{c}\right]$} & \multicolumn{4}{|c|}{$f(T)=p\left[1-\left(\frac{T-q}{T_{m}-q}\right)^{r}\right]$} \\
\hline & $a$ & $b$ & $c$ & RMSE & $p$ & $q$ & $r$ & RMSE \\
\hline L2001 & 0.44 & 23.12 & 2.93 & 0.006 & 0.42 & 22.15 & 2.06 & 0.031 \\
\hline K2001 & 0.44 & 23.66 & 2.34 & 0.011 & 0.42 & 23.79 & 3.62 & 0.007 \\
\hline Total data & 0.44 & 23.44 & 2.75 & 0.021 & 0.42 & 22.33 & 2.50 & 0.039 \\
\hline
\end{tabular}

Ref. Unit of $\alpha, p$, and RMSE $=[1 / \mathrm{day}]$. Unit of $b$ and $q={ }^{\circ} \mathrm{C}$ Unit of $c$ and $r=[-$, dimensionless $]$

Table 6. Optimal parameter values and RMS errors of the $C$. polykrikoides growth rate in the salinity conditions for each data set

\begin{tabular}{ccccc}
\hline \hline \multirow{2}{*}{ Reference data } & \multicolumn{4}{c}{$f(S)=\alpha\left(\frac{S}{\beta}\right)^{\gamma} \exp \left[1-\left(\frac{S}{\beta}\right)^{\gamma}\right]$} \\
\cline { 2 - 5 } & $\alpha$ & $\beta$ & $\gamma$ & RMSE \\
\hline L2001 & 0.37 & 32.16 & 3.05 & 0.027 \\
K2001 & 0.38 & 32.30 & 1.12 & 0.013 \\
Total data & 0.37 & 31.35 & 1.98 & 0.073 \\
\hline
\end{tabular}

Ref. Unit of $\alpha$ and RMSE $=[1 /$ day $]$. Unit of $\beta=$ PSU. Unit of $\gamma=[-$, dimensionless]

의 Michaelis-Menten 함수와 광저해 효과를 표현하는 함수를 이 용하여 매개변수와 RMS 오차를 추정하였다(Table 3 참조). 추 정결과 C. polykrikoides 적조생물은 실험구간 내에서의 광도에 서는 광저해 효과가 미약하여 수정된 Michaelis-Menten 함수로 보다 적절하게 표현되고 있는 것으로 파악되었다. 그러나 연구 자에 따라 실험에 사용한 광도범위가 크게 차이나고, 자료의 변 동 범위도 크게 차이가 나고 있음을 알 수 있다(Fig. 1(a) 참조 ). 특히 성장률 계수에서 범위가 0.30-0.58(1/day)로 크게 차이가 나고 있으나, 실험 광도범위가 넓은 K2001 자료에서 추정한 함 수형태를 선택하였으며, 성장률 계수 변동 범위는 본 연구에서 분석한 성장제한인자가 아닌 다른 요인에 의한 것으로 판단된 다. 한편 본 실험 자료에서 사용한 광도의 단위는 $\mu \mathrm{mole} / \mathrm{m}^{2} / \mathrm{s}$ 이 기 때문에 기상자료로 제공되는 광도(일사량, irradiance)를 사 용하는 경우에는 $M J / m^{2}$ (또는 Langleys $=$ calorie $/ \mathrm{cm}^{2}$ )로 환산하 여야 한다. 광도(또는 조도)의 단위는 매우 다양하기 때문에 환
산과정에서 주의가 필요하다(Meyer-Arendt, 1968; Murphy Jr., 2012). 이 환산과정은 다소 복잡하여 파장에 따른 태양복사량 효율 정보와 실험실에서 사용한 광원의 스펙트럼 정보를 이용 하여 추정하게 된다(Thimijan and Heins, 1983; Shim, 2003). 조류 성장실험에 널리 이용되는 백색 형광램프의 경우, Luminous efficacy $\left(\mathrm{mW} / \mathrm{lm}=\mathrm{mW} /\left(\mathrm{lux} / \mathrm{m}^{2}\right) \fallingdotseq 2.93-3.49\right.$ 정도로 제시되고 있다. 따라서 다음과 같이 어느 정도의 범위를 가지 는 환산공식 (2)-(3)이 적용된다. Table 4에 제시된 매개변수에 서 $\beta, b$ 는 단위가 광도 단위를 사용하기 때문에, 단위를 변환 하는 경우 이 두 매개변수도 단위를 변환하여 사용하여야 한다.

$$
\begin{aligned}
& 100 \mu \mathrm{mole} / \mathrm{m}^{2} / \mathrm{s} \fallingdotseq 7,386 \mathrm{lux}=21.6 \mathrm{~W} / \mathrm{m}^{2} \\
& =44.6 \mathrm{Ly} / \text { day }=1.86 \mathrm{MJ} / \mathrm{m}^{2} / \text { day }(\text { Thimijan and Heins, 1983) }
\end{aligned}
$$

$100 \mu \mathrm{mole} / \mathrm{m}^{2} / \mathrm{s} \fallingdotseq 6,300$ lux $=22.0 \mathrm{~W} / \mathrm{m}^{2}$

$=45.4 \mathrm{Ly} / \mathrm{day}=1.90 \mathrm{MJ} / \mathrm{m}^{2} /$ day $($ Shim, 2003)

광도와는 달리 수온에서는 최적 조건이 명확하게 나타나고 있다. C. polykrikoides 성장은 광도 증가에 따라 전체적으로 성장하는 양상을 보이는 반면, 수온의 경우에는 최적 수온에 서 벗어날수록 성장률은 급격화게 감소하는 양상을 뚜렷하게 보이며, 여러 연구자의 자료의 편차도 매우 적게 나타나고 있 다(Fig. 1 (b) 참조). 추정된 최적 수온은 $23.1-23.7^{\circ} \mathrm{C}$ 정도이 며, 최적조건에서 벗어나는 함수의 감소정도를 조정할 수 있 는 일반적인 형태의 지수함수(간단한 조건을 개선)를 이용하 여 매개변수를 추정하였다. 
Table 7. Optimal parameter values and RMS errors of the $C$. polykrikoides growth rate in the nutrient concentration conditions for each data set

\begin{tabular}{|c|c|c|c|c|c|}
\hline \multicolumn{6}{|c|}{ (a) Nitrate and phosphate concentrations $(\mu M)$} \\
\hline & & \multicolumn{4}{|c|}{$f\left(N O_{3}\right)=a\left(\frac{N O_{3}+c}{N O_{3}+b}\right), f\left(P O_{4}\right)=a\left(\frac{P O_{4}+c}{P O_{4}+b}\right)$} \\
\hline & & $a(1 /$ day $)$ & $b(\mu M)$ & $c(\mu M)$ & $\begin{array}{l}\text { RMSE } \\
\text { (1/day) }\end{array}$ \\
\hline \multirow{2}{*}{ L2001 } & Nitrate & 0.37 & 26.47 & 12.74 & 0.024 \\
\hline & Phosphate & 0.41 & 0.95 & 0.03 & 0.025 \\
\hline \multirow{2}{*}{ K2001 } & Nitrate & 0.36 & 11.14 & 4.28 & 0.035 \\
\hline & Phosphate & 0.42 & 1.49 & 0.30 & 0.031 \\
\hline G2012 & Nitrate & 0.45 & 4.34 & 2.95 & 0.009 \\
\hline \multirow{2}{*}{ Total data } & Nitrate & 0.38 & 7.05 & 2.62 & 0.048 \\
\hline & Phosphate & 0.42 & 1.42 & 0.24 & 0.032 \\
\hline
\end{tabular}

(b) Ammonium concentrations $(\mu M)$

Reference data

$$
f\left(N H_{4}\right)=\alpha\left(\frac{N H_{4}}{\beta}\right)^{\gamma} \exp \left[1-\left(\frac{N H_{4}}{\beta}\right)^{\gamma}\right]
$$

\begin{tabular}{|c|c|c|c|c|}
\hline & \\
\hline & $\alpha$ (1/day) & $\beta(\mu M)$ & $\gamma(-)$ & $\begin{array}{l}\text { RMSE } \\
\text { (1/day) }\end{array}$ \\
\hline L2001 & 0.38 & 30.52 & 0.43 & 0.021 \\
\hline K2001 & 0.38 & 27.90 & 0.41 & 0.021 \\
\hline G2012 & 0.44 & 99.99 & 0.49 & 0.019 \\
\hline Total data & 0.39 & 44.45 & 0.45 & 0.051 \\
\hline
\end{tabular}

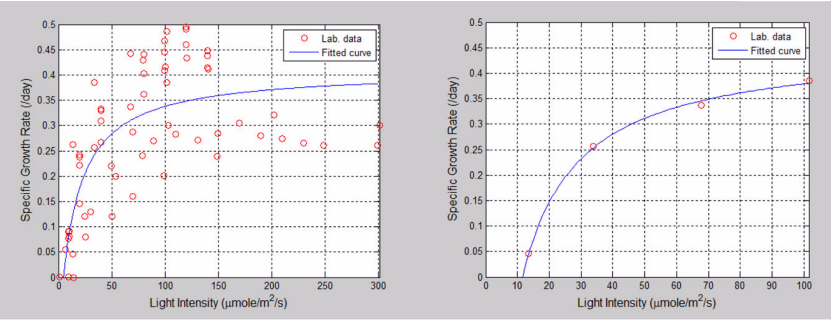

(a) Light intensity $\left(\mu \mathrm{mole} / \mathrm{m}^{2} / \mathrm{s}\right)$

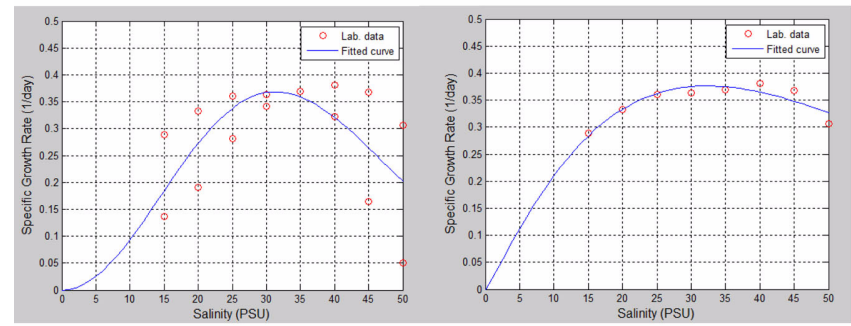

(c) Salinity (PSU)

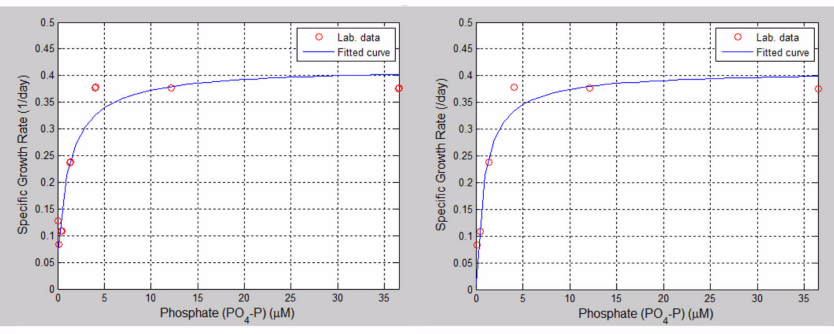

(e) Phosphate concentrations ( $\mu M$

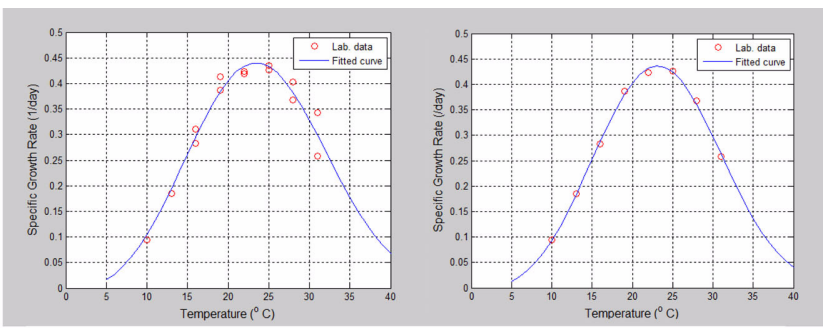

(b) Water temperature $\left({ }^{\circ} \mathrm{C}\right)$

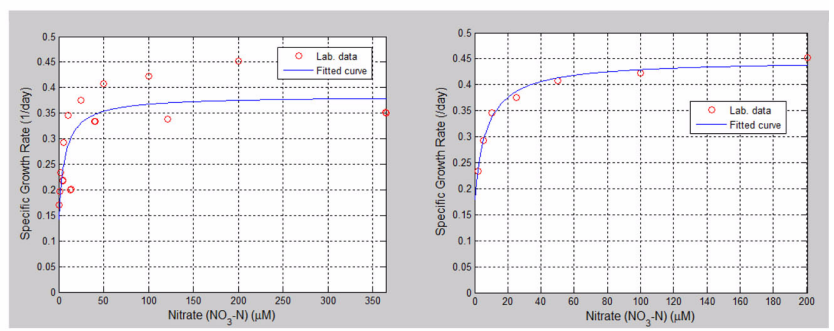

(d) Nitrate concentrations $(\mu M)$

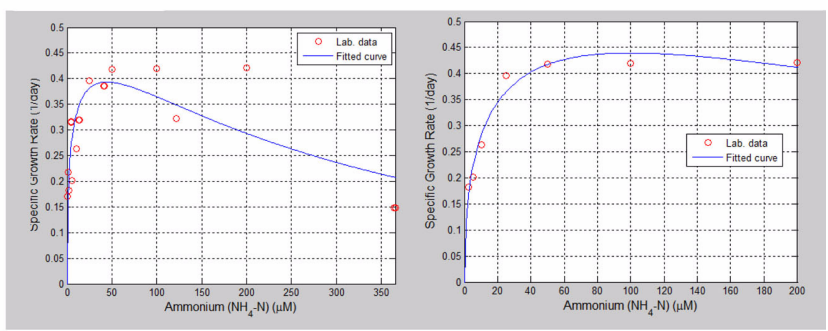

(f) Ammonium concentrations $(\mu M)$

Fig. 1. Optimal fitting-function forms for the C. polykrikoides growth (left panel = in case of using all data set, right panel = in case of the specific one data set showing the minimum RMS error, see the gray cells of the Tables 4-7) 
염분변화에 따른 성장률변화도 수온변화 양상을 표현하기 위 하여 사용한 함수형태와 동일함 형태의 함수를 사용하였다. 염 분 변화에 따른 성장인자 제한함수는 다른 인자에 비하여 제시 되는 형태가 많지 않으나, 전체적인 성장률 변화양상이 최적 조 건이 포함된 함수형태와 유사하여(Fig. 1 (c) 참조) 수온조건에 서 사용한 함수형태를 이용하였다. 최적 염분 조건으로 추정된 매개변수는 31.4-32.3 PSU 범위로 파악되었다. 수온과 염분의 영 향은 독립적으로 표현하는 방식 $\left(=f_{1}(T) \cdot f_{2}(S)\right)$ 과 더불어 종속 적으로 표현하는 방식 $\left(=f_{1}(T, S)\right)$ 도 사용되고 있다. Oh et al.(2010)은 수온과 염분 동시변화에 따른 성장속도 실험결과 자 료를 중회귀분석(multiple regression)으로 다음과 같은 식 (4)를 제안하였다. 한편, Kim et al.(2004)도 같은 형태의 식 (5)를 제 안한 바 있다. Yamatogi et al.(2005)은 Contour 도시를 제시한 바 있으며, 최적조건으로 수온은 $27.5^{\circ} \mathrm{C}$, 염분 범위는 28-32 PSU 범위이며, 이 조건에서의 최대 성장률은 Oh et al.(2001)이 제시한 $25^{\circ} \mathrm{C}, 30 \mathrm{PSU}$ 조건에서의 $0.351 / \mathrm{day}$, Kim et al.(2004) 이 제시한 $25^{\circ} \mathrm{C}, 34 \mathrm{PSU}$ 조건에서의 $0.41 \mathrm{1} / \mathrm{day}$ 보다 $34-57 \%$ 이상 높은 $0.551 / \mathrm{day}$ 이상으로 제시되고 있다. 그러나 염분 변 화 범위가 하구를 제외한 연안 해역에서는 크지 않고, 염분 변 화에 따른 성장률 변화 구배가 수온에 비하여 미미하기 때문에 독립적으로 취급하여도 그 오차는 미미한 수준으로 파악되었다 . 그러나 특정 수온 조건에서는 염분에 따른 성장률 구배가 크 기 때문에 보다 적절한 염분 조건에서의 성장률을 수온의 함수 로 표현하는 종속적인 형태의 함수를 검토할 필요가 있을 것으 로 사료된다. 그러나 제시된 성장함수는 다항함수 형태이며, 수 온과 염분 각각에 대한 다항함수 형태로 인수분해를 하면 각각 의 영향인자를 독립적으로 표현한 본 연구 방식과 동일하게 된 다. 식 (4)-(5)를 이용한 표현방식은 성장 제한함수를 제한인자 의 변동 범위에서 각각 3 차 다항식으로 표현하고, 본 연구에서 는 최적함수 형태로 표현한 차이로 함수 선택의 차이에 불과하다.

$$
\begin{aligned}
\mu= & -0.05 S+\left(2.0 T^{2}+3.0 S^{2}\right) \cdot 10^{-3} \\
& +\left(-7.6 T^{3}-3.5 S^{3}+4.6 T^{2} S-3.5 T S^{3}\right) \cdot 10^{-5} \\
& \fallingdotseq\left(a+b T+c T^{2}+d T^{3}\right) \cdot\left(e+f S+g S^{2}+h S^{3}\right)
\end{aligned}
$$

$$
\begin{aligned}
\mu= & 0.946-0.177 T-0.0474 S+0.01218 T^{2} \\
& +0.0026745 S^{2}-0.0002375 T^{3}-0.00004003 S^{3} \\
& \fallingdotseq\left(a+b T+c T^{2}+d T^{3}\right) \cdot\left(e+f S+g S^{2}+h S^{3}\right)
\end{aligned}
$$

한편 영양염류 농도변화에 따른 성장률 변화 자료는 질산 염과 인산염이 포화함수 형태의 변화양상을 보이는 반면, 암 모니아 농도의 경우에는 포화함수와 유사하지만 고농도 조건 에서 최적 조건 형태의 변화양상을 보여(Fig. 1 (d)-(f) 참조), 서로 다른 형태의 함수를 이용하였다. 최적 영양염류 농도변 화에 따른 성장률변화는 아주 낮은 농도에서는 작은 농도증 가에도 급격한 성장률 증가가 보이고 있으나, 어느 정도 높은 농도조건(100 $\mu M$ 이상)에서는 성장률이 일정한 수준을 유지 (질산염 및 인산염 농도)하거나 오히려 감소(암모니아 농도)하 는 경향을 보이고 있다. 영양염류 농도변화에 따른 성장률 변 화도, 영양염류 농도가 $\mu \mathrm{Mole}$ 단위로 제시되기 때문에 보통 의 조건에서는 $\mathrm{mg} / \mathrm{L}$ 단위로 환산하는 과정이 필요하며, 이 환산과정에서는 질산염, 인산염의 경우 $b, c$ 매개변수, 암모 니아의 경우 $\beta$ 매개변수도 농도환산을 하여야 한다. 환산공 식은 영양염류 $(\mu \mathrm{M}=\mu \mathrm{mole} / L$, 물질의 $1 \mathrm{~mole}$ 당 분자량, $\mathrm{NO}_{3}=62 \mathrm{~g}, \mathrm{NO}_{4}=18 \mathrm{~g}, \mathrm{PO}_{4}=95 \mathrm{~g}$ )에 따라 다음과 같이 식 (6)으로 표현된다.

$$
\begin{aligned}
& 100 \mu M\left(\mathrm{NO}_{3}-\mathrm{N}\right)=6.2 \mathrm{mg} / \mathrm{L}\left(\mathrm{NO}_{3}-\mathrm{N}\right) \\
& 100 \mu M\left(\mathrm{PO}_{4}-\mathrm{P}\right)=9.5 \mathrm{mg} / \mathrm{L}\left(\mathrm{PO}_{4}-\mathrm{P}\right) \\
& 100 \mu M\left(\mathrm{NH}_{4}-\mathrm{N}\right)=1.8 \mathrm{mg} / \mathrm{L}\left(\mathrm{NH}_{4}-\mathrm{N}\right)
\end{aligned}
$$

\section{4. 결론 및 제언}

가용한 환경조건과 C. polykrikoides 성장속도 변화에 대한 자료를 이용하여 최적의 함수와 매개변수를 추정하여 $C$. polykrikoides 성장모형을 구성하였으며, 최적 추정된 성장모 형은 다음 식 (7)로 표현되며, 식에 포함된 매개변수 및 함 수형태는 Table 8에 제시하였다. 최적 성장조건은 수온, 염분 및 암모니아 농도에서 나타났으며, 각각 $23.1^{\circ} \mathrm{C}, 32.3 \mathrm{PSU}$,

Table 8. Mathematical growth model of the C. polykrikoides

\begin{tabular}{ccc}
\hline \hline Growth factor & Function types & $\mu_{\max }$ \\
\hline $\begin{array}{c}\text { Light intensity } \\
\left(\mu \mathrm{mol} / \mathrm{m}^{2} / \mathrm{s}\right) \\
\text { Water temperature } \\
\left({ }^{\circ} \mathrm{C}\right)\end{array}$ & $f_{1}(I)=\frac{I-11.54}{I+6.19}$ & 0.45 \\
$\begin{array}{c}\text { Salinity } \\
(\mathrm{PSU})\end{array}$ & $f_{2}(T)=\left(\frac{T}{23.12}\right)^{2.93} \cdot \exp \left[1-\left(\frac{T}{23.12}\right)^{2.93}\right]$ & 0.44 \\
\hline \multirow{2}{*}{ Nutrients } & $f_{3}(T)=\left(\frac{S}{32.30}\right)^{1.12} \cdot \exp \left[1-\left(\frac{S}{32.30}\right)^{1.12}\right]$ & 0.38 \\
\hline $\begin{array}{c}\text { Ammonium } \\
\left(\mu \mathrm{mol}-\mathrm{NH}_{4}\right) \\
\text { Nitrate } \\
\left(\mu \mathrm{mol}-\mathrm{NO}_{3}\right) \\
\text { Phosphate } \\
\left(\mu \mathrm{mol}-\mathrm{PO}_{4}\right)\end{array}$ & $f_{44}\left(N H_{4}\right)=\left(\frac{N H_{4}}{99.99}\right)^{0.49} \cdot \exp \left[1-\left(\frac{N H_{4}}{99.99}\right)^{0.49}\right]$ & 0.44 \\
& $f_{4 N}\left(N O_{3}\right)=\frac{N O_{3}+2.95}{N O_{3}+4.34}$ & 0.45 \\
\hline
\end{tabular}


$100 \mu M$ 로 파악되었다. 광도와 영양염류의 경우, 개선된 Michaelis-Menten 함수식을 사용하였으나, 함수 형태에서 반 포화 상수에 해당하는 수치는 광도의 경우 $6.19 \mu \mathrm{mole} / \mathrm{m}^{2} / \mathrm{s}$, 질산염 및 인산염의 경우 각각 $4.34 \mu \mathrm{M}, 0.95 \mu \mathrm{M}$ 로 파악되 었다. 한편 C. polykrikoides 적조생물의 성장인자에 해당하 는 빛, 온도, 염분 및 영양염류 등의 모든 조건이 완벽하게 충족되는 경우의 최대 성장속도는 0.38-0.45 1/day 범위이다.

$$
G_{P}=\mu_{\max } f_{1}(I) \cdot f_{2}(T) \cdot f_{3}(S) \cdot f_{4}(N)
$$

여기서, $f_{4}(N)=f_{4 A}\left(N H_{4}\right) \cdot f_{4 N}\left(N O_{3}\right) \cdot f_{4 P}\left(P_{4}\right)$ 이다.

본 연구에서 사용한 환경인자와 적조성장속도에 관한 자료 는 실험실 조건에서 수행되었기 때문에 현장에서는 어느 정 도의 차이가 발생할 수 있다. 따라서 구성된 C. polykrikoides 모형을 이용하여 가용한 현장자료를 이용한 모형의 검정이 필 요할 것으로 판단된다. 환경 인자를 제어할 수 있는 실험 자 료와는 달리 현장에서는 모든 환경인자가 상호 영향을 미치 며 시간적-공간적으로 변화하기 때문에 C. ploykrikoides 성 장률도 시간적·공간적으로 변화하게 되며, 최대 조류 성장률 만이 특정 해역에서 일정한 값을 가지는 상수로 취급된다. 따 라서 이러한 가정을 포함하고 있는 환경 인자가 모형 검정을 통하여 현장과 실험 자료의 정량적인 차이 또는 구조적인 차 이를 파악할 수 있다면 보다 실용적인 적조 성장모형 구성이 가능할 것으로 판단된다. 또한 C. polykrikoides 적조생물이 다른 작은 플랑크톤에 대한 섭식행동을 하여 성장한다는 Jeong et al.(2004, 2010)의 연구 성과도 있기 때문에 섭식특 성을 고려 등의 한 성장모형의 개발도 필요하며, 조류의 성 장과 반대되는 사멸속도(mortality rate)에 관한 모형 구성도 필요할 것으로 판단된다. 더불어 실질적인 활용을 위해서는 호흡률, 분비율, 배설률 및 동물플랑크톤의 섭식률(grazing rate) 등의 항목도 추가하여 C. polykrikoides 모형으로 완성 할 필요가 있다.

\section{감사의 글}

본 논문은 2014년 해양수산부의 재원으로 한국해양과학기 술진흥원의 지원을 받아 수행된 연구(운용해양(해양예보) 시 스템 연구 (2단계) - PM57701)입니다. 연구비 지원에 감사 드립니다.

\section{References}

Bowie, G.L., Mills, W.B., Porcella, D.B., Campbell, C.L., Pagenkopf, J.R., Rupp, G.L., Johnson, K.M., Chan, P.W.H., Gherini, S.A., Chamberlin, C.E., and Barnwell, B.O. 1985. Rates, Constants, and Kinetics Formulations in Surface Water Quality
Modeling, Second Edition, Environmental Research Lab., EPA/ 600/3-85/040. US. EPA.

Gobler, C.J., Burson, A., Koch, F., Tang, Y and Mulholland, M.R. 2012. The role of nitrogenous nutrients in the occurrence of harmful algal blooms caused by Cochlodinium polykrikoides in New York estuaries (USA). Harmful Algae, 17:64-74

Jeong, H.J., Yoo, Y.D., Kim, J.S., Kim, T.H., Kim, J.H., Kang, N.S. and Yih, W.H., 2004. Mixotrophy in the phototrophic harmful alga Cochlodinium polykrikoides (Dinophycean): prey species, the effects of prey concentration and grazing impact, J. of Eukaryotic Microbiology, 52, 563-369.

Jeong, H.J., Yoo, Y.D., Kim, J.S., Seong, K.A., Kang, N.S., and Kim, T.H. 2010. Growth, feeding, and ecological roles of the mixotrophic and heterotrophic dinoflagellates in marine planktonic food webs, Ocean Science Journal, 45, 65-91.

Jorgensen, S.E. and Bendoricchio, G. 2001. Fundamentals of Ecological Modeling, Third Edition, Chap. 7, Elsevier.

Kim DI, Matsuyama Y, Nagasoe S, Yamagughi M, Yoon YH, Oshima Y, Imada N, Honjo T, 2004. Effects of temperature, salinity and irradiance on the growth of the harmful red tide dinoflagellate Cochlodinium polykrikoides Margalef (Dinophyceae), J. Plankton Research, 26(1):61-66

Kim HC, Lee CK, Lee SG, Kim HG, Park CK, 2001. PhysicoChemical Factors on the Growth of Cochlodinium polykrikoides and Nutrient Utilization, J. Kor Fish Aquat Sci. 34(5):445-456

Lee CK, Kim HC, Lee SG, Jung CS, Kim HG, Lim WA, 2001. Abundance of Harmful Algae, Cochlodinium polykrikoides, Gyrodinium impudicum and Gymnodinium catenatum in the Coastal Area of South Sea of Korea and Their Effects of Temperature, Salinity, Irradiance and Nutrient on the Growth in Culture, J. Kor Fish Aquat Sci. 34(5):536-544

Lee, C.K, Park, T.G., Park, Y.T., and Lim, W.A. 2013. Monitoring and trends in harmful algal blooms and red tides in Korean coastal waters, with emphasis on Cochlodinium polykrikoides, Harmful Algae, 30S, S3-S14.

Lim, W.-A. 2004. Studies on the Initiation of Cochlodinium ploykrikoides Bloom in the Southern Waters of Korea. Ph. D. Thesis, Pusan National University (in Korean).

Meyer-Arendt, J.R., 1968. Radiometry and photometry: Units and conversion factors, Applied Optics, 7(10), 2081-2084.

Ministry of Oceans and Fisheries, 2014. Methods on the red-tide monitoring in advance, forecasting, and potential damage prevention, MOF Instruction, No. 163. (2014. 3. 18. in Korean)

Murphy, Jr., T.W., 2012. Maximum spectral luminous efficacy of white light, J. of Applied Physics, 111, 104909:1-6.

Oh SJ, Kim CH, Kwon HK, Yang HS, 2010. Effects of Water Temperature, Salinity and Irradiance on the Growth of Harmful Dinoflagellate Cochlodinium polykrikoides Margelef isolated from South Sea of Korea in 2008. J. Kor Fish Aquat Sci. 43(6):715-722

Oh SJ, Yoon YH, Kim DI, Shimasaki Y, Oshima Y, Honjo T, 2006. Effects of Light Quantity and Quality on the Growth of the Harmful Dinoflagellate, Cochlodinium polykrikoides Margalef 
(Dinophyceae), Algae, 21(3):311-316.

Seoul National University, 2014. Planning Research on the Harmful Cochlodinium polykrikoides Bloom mechanism and Warning System Establishment, Ministry of Science, ICT and Future Planning (in Korean).

Shim, J.H. 2003. Plankton Ecology, Chap. 2, Seoul National University.

Thimijan, R.W. and Heins, R.D., 1983. Photometric, radiometric, and quantum light units of measure: A review of procedures for inter-conversion, HortScience, 18(6), 818-822.

Yamatogi T, Sakaguti M, Takagi N, Iwataki M, Matsuoka K, 2005.
Effects of temperature, salinity and light intensity on the growth of a harmful dinoflagellate Cochlodinium polykrikoides Margalef occurring in coastal waters of West Kyushu, Japan. Bull. Plankton Soc. Japan 52(1):4-10 (in Japanese)

원고접수일: 2014년 7월 28일

수정본채택: 2014년 8월 13일(1차)

2014년 8월 21일(2차)

게재확정일: 2014년 8월 26일 